\title{
A Comunidade de Prática Xerente e suas matemáticas
}

\author{
The Xerente Community of Practice and its Mathematics
}

\author{
Elisângela Aparecida Pereira de Melo ${ }^{1}$ \\ Tadeu Oliver Gonçalves ${ }^{2}$
}

\begin{abstract}
Resumo
Neste artigo apresentamos as práticas das pinturas corporais das metades clânicas exogâmicas patrilineares Doi e Wahirê, do povo indígena Xerente, cujo objetivo foi investigar as matemáticas potencializadas nas simbologias encontradas nas pinturas corporais Doi e Wahirê; questionando em que termos as simbologias encontradas nas pinturas corporais de pertencimento dos indígenas nas metades exogâmicas patrilineares Doi e Wahirê constituem um sistema de matemáticas Xerente. As articulações teóricas deram-se a partir da teoria de comunidades de prática proposta por Wenger (2001). A investigação foi desenvolvida mediante a abordagem da pesquisa qualitativa etnográfica. A recolha das informações ocorreu nos contextos comunitários das aldeias Porteira e Salto, por meio do observar para participar e do participar para observar os indígenas em comunidades de prática. As análises sobre essas simbologias sinalizam possibilidades de estudos investigativos das geometrias, a partir dos desenhos clânicos de cada metade exogâmica deste povo.
\end{abstract}

Palavras-chave: Pinturas corporais Xerente; Comunidades de prática; sistema de matemáticas Xerente.

\begin{abstract}
In this article we present the body painting practices of the patrilineal exogamous clan halves - Doi and Wahirê, of the indigenous Xerente people, whose objective was to investigate the mathematics potentialized in the symbologies found in the body paintings Doi and Wahirê; so we questioned in what terms the symbologies found in the bodily paintings of indigenous belonging to the patrilineal exogamous halves Doi and Wahirê constitute a system of Xerent mathematics. The theoretical articulations were made based on the theory of communities of practice proposed by Wenger (2001). The research was developed through the qualitative ethnographic research approach. Information gathering took place in the community contexts of Porteira and Salto villages, through observing to participate and to participate to observe the indigenous in communities of practice. The analyzes on these symbologies indicate possibilities of investigating studies of geometries, from the clan drawings of each exogamic half of this people.
\end{abstract}

Keywords: Xerente body paintings; Communities of practice; Xerente math system. mathematics system

\section{Contextualizando a pesquisa}

Neste artigo, abordamos a prática tradicional das simbologias encontradas nas pinturas corporais clânicas das metades exogâmicas patrilineares ${ }^{3}$ que são Doi $e$ Wahirê $\hat{e}^{4}$

\footnotetext{
${ }^{1}$ Doutora em Educação em Ciências e Matemáticas. Professora da Universidade Federal do Tocantins (UFT), Câmpus de Araguaína, Curso de Licenciatura em Matemática; Tutora do Grupo PET/Conexões de Saberes Indígenas e Líder do Grupo Grupo de Pesquisa em Educação Matemática do Norte do Tocantins (GEPEM-TO). E-mail: elisangelamelo@uft.edu.br.

${ }^{2}$ Doutor em Educação Matemática. Professor da Universidade Federal do Pará (UFPA), Instituto de Educação Matemática e Científica e do Programa de Pós-graduação em Educação em Ciências e Matemáticas. E-mail: tadeuoliver@yahoo.com.br.
} 
suas subdivisões entre os Doi (os donos das pinturas em bolinhas - kritoizapto/círculo) e os Wahirê (os donos das pinturas em listra - ihirê/traço), do povo indígena Xerente, as quais fazem parte de um repertório compartilhado, cujo engajamento dos membros - os indígenas ocorre pela filiação patrilinear.

Assim, os elementos socioculturais empreendidos e mobilizados nesta prática de pertencimento clânico, constituíram parte de nossas investigações, discussões, reflexões e análises compartilhadas com os colaboradores ${ }^{5}$ por meio da pesquisa de doutorado, intitulada "Sistema Xerente de Educação Matemática: negociações entre práticas socioculturais e comunidades de prática", já concluída ${ }^{6}$.

Sob essa perspectiva, constituímos a empiria da pesquisa nas aldeias indígenas Porteira e Salto, do povo Xerente, localizadas no município de Tocantínia, Região Central do estado do Tocantins. Contudo, na elaboração deste artigo, tomamos como base as vivências e as experiências dos indígenas residentes nessas aldeias, considerando as dimensões da prática como propriedade de uma comunidade de prática, tal como proposto por Wenger (2001).

A coleta das informações junto aos colaboradores, sobre as práticas de pertencimentos dos indígenas nas metades exogâmicas patrilineares Doi e Wahirê, ocorreu segundo os preceitos da abordagem qualitativa, a partir da pesquisa etnográfica, pautada na participação para observar e do observar para participar como indica Guber (2012), as quais permitiram compreender a complexidade dos saberes socioculturais e, em colaboração com os indígenas, refletir sobre as potencialidades cognitivas e educativas dos desenhos encontrados nas pinturas corporais, dentre outros saberes e fazeres na prática, que evidenciam, também, a arte do povo Xerente.

Das informações recolhidas nos contextos investigados, nos remetemos à discussão da negociação ocorrida entre os educadores Xerente, a comunidade em especial, os anciãos, e nós - como pesquisadores, quanto à parte das práticas das pinturas corporais clânicas a serem alvo da pesquisa.

Nessa direção, as discussões e reflexões aqui apresentadas referem-se a um sistema sociocultural de matemáticas Xerente potencializadas nas práticas dos indígenas no saber fazer das pinturas corporais, e questionam: em que termos as simbologias encontradas nas pinturas corporais de pertencimento dos indígenas nas metades exogâmicas patrilineares $D o i$

\footnotetext{
${ }^{3}$ Sistema tradicional Xerente de organização e de pertencimento do(s) filho(s) e filha(s) nas práticas e nos fazeres socioculturais do pai, nos partidos ou nas metades das pinturas corporais clânicas.

${ }^{4}$ Essas metades clânica e patrilineares, que são os Doi, representam a Lua e os Wahirê representam o Sol, que são também os mitos duais criadores do povo Xerente. Portanto, é no encontro entre esses dois clãs que ocorre a unicidade. São eles os mitos de origem da criação dos diferentes padrões da pintura clânica dos Xerente. São esses partidos ou metades, também, os responsáveis por toda a organização da tradição deste povo, quer seja a cultural ou a social, na unidade do encontro com o outro.

5 Refere-se particularmente à participação direta ou indireta dos indígenas no decurso de realização da pesquisa, que abrangeu laços de amizades, de confiança, de interação, de trocas de experiências, de colaboração, de doação de tempo, dentre outros, que se constituíram em diferentes métodos e técnicas de recolha de informaçõos e, estes ultrapassaram os limites, os conceitos teóricos e os metodológicos estabelecidos pela academia.

6 Disponível em: http://www.ppgecm.propesp.ufpa.br/index.php/br/teses-e-dissertacoes/teses/190-teses-2016.

Zetetiké, Campinas, SP, v.26, n.1, jan./abr. 2018, p.59-74

ISSN 2176-1744
} 
e Wahirê constituem um sistema de matemáticas Xerente? Para tanto, objetivamos: investigar as matemáticas potencializadas nas simbologias encontradas nas pinturas corporais Doi $e$ Wahirê.

Entretanto, as reflexões provenientes do desenvolvimento desse sistema sociocultural das matemáticas em sala de aula serão discutidas em estudos futuros, nas perspectivas indicadas por Brasil (2005) e por Melo (2016), abordando a questão interdisciplinar de forma diferenciada, intercultural e bilíngue, no sentido de favorecer o diálogo entre as práticas tradicionais Xerente e a ação didática e pedagógica dos educadores Xerente, com o ensino e a aprendizagem das matemáticas, junto aos estudantes de sua comunidade.

Os entrelaçamentos foram propiciados pelo campo teórico de comunidades de prática e pelas abordagens metodológicas, ora provenientes da pesquisa qualitativa etnográfica, ora provenientes dos nossos colaboradores, de modo que estruturamos o artigo em três seções.

A primeira está sob a égide dos aportes teóricos relacionados às comunidades de prática propostos por Wenger (2001), ao destacar as três dimensões da prática como propriedade essencial em uma comunidade de prática, a saber: o engajamento mútuo, o empreendimento conjunto e o repertório compartilhado. Ao consideramos essa abordagem, também destacamos a discussão dos termos 'comunidades' e 'prática' favorecendo o diálogo e as convergências entre a teoria e as práticas do saber fazer na vivência dos indígenas, em suas comunidades de práticas socioculturais.

A segunda seção é dedicada aos caminhos metodológicos trilhados para a recolha de informações nos contextos investigados e junto aos colaboradores. Na terceira seção, descrevemos os processos socioculturais de pertencimentos dos indígenas Xerente nas metades clânicas patrilineares Doi e Wahirê, na perspectiva de sistematizarmos um sistema de matemáticas Xerente, presente nas simbologias das pinturas corporais dessas metades clânicas, conforme mostra a Figura 01, apresentada na referida seção.

Por fim, apresentamos nossas considerações acerca das interconexões interpretativas que suscitam sentido e significado às aprendizagens dos estudantes, em contexto da diversidade de saberes.

\section{Comunidades de prática}

Na perspectiva de constituirmos os itinerários teóricos que pudessem dialogar com os saberes tradicionais e práticos do povo indígena Xerente, motivados pelas relações de aprendizagens socioculturais, coletivas e compartilhadas entre os indígenas, assumimos os conceitos de comunidades de prática abordados por Wenger (2001).

$\mathrm{Na}$ conceituação epistemológica do referido autor, vários aspectos são considerados para definirem e/ou constituírem comunidades de prática, particularmente três dimensões características das comunidades de prática, a saber: o engajamento mútuo, o empreendimento conjunto e o repertório compartilhado, as quais se relacionam entre si, de modo que a prática 
se converte em uma propriedade da comunidade. Essas três dimensões são assim compreendidas:

- $\quad$ O engajamento mútuo - definido pelos membros da comunidade, quando estes realizam ações conjuntas, trocam experiências, compartilham conhecimentos, aprendem juntos, dialogam sobre assuntos diversos, resolvem problemas, mas tendo em si um compromisso coletivo que os ligam diretamente à comunidade de prática;

- $\quad$ O empreendimento conjunto - definido pelas competências que se esperam de seus membros na realização das práticas;

- $\quad$ O repertório compartilhado - reflete uma história de mútuo engajamento de seus membros na comunidade, permitindo a eles evidenciarem as distintas formas pelas quais uma história pode ser contada e recontada de modo a gerar novos significados e sujeitos de negociação.

Mediante essas compreensões, optamos por apresentar uma caracterização do conceito de comunidades de prática e seus elementos, assim como, as contribuições dessa teoria para nossa compreensão quanto à organização social e cultural do povo Xerente como uma comunidade de prática, considerando o engajamento dos indígenas em suas práticas tradicionais por filiação patrilinear, que compartilham um repertório de saberes apreendidos e transmitidos de geração a geração pela oralidade, pela simbologia visual e pela prática do saber fazer na prática.

Os estudos de Wenger sobre comunidades de prática pautam-se em pesquisas realizadas com Lave \& Wenger (1991), ao tomarem suas experiências advindas de distintos campos do conhecimento como a Antropologia, com destaque às práticas etnográficas vividas por Lave com indivíduos de distintas realidades socioculturais, constituindo assim, as teorias sobre aprendizagem social e comunidades de prática.

Em parceria, estes pesquisadores começaram a desenvolver estudos de modo a construir uma nova teoria baseada em aprendizagens sociais, centrada na atividade, na cultura e no contexto, construída e desenvolvida coletivamente nas comunidades culturalmente distintas.

Essas pesquisas foram centradas em diversos contextos e realidades socioculturais, porém, pautadas em abordagens antropológicas e em empirias próprias. Assim, Lave et al. (1991) revisitaram seus repertórios teóricos aliados às suas experiências sobre a teoria da aprendizagem social. Definiram então, os termos 'comunidades' e 'prática', tendo como premissa compreender a aprendizagem em um processo de construção humana e identitária referente à participação e ao engajamento nas atividades que favoreciam aprendizagens, e não como um artefato cultural compartilhado, de modo que:

O termo comunidade, não implica necessariamente a uma entidade cultural primordial compartilhada. Assumimos que os membros têm diferentes interesses e fazem diversas contribuições para que a atividade mantenha pontos de vista variados. Em nossa opinião, a participação em múltiplos níveis está implicada em pertencer a uma 
comunidade de prática. O termo comunidade também não implica, necessariamente, uma co-participação em um grupo identificável bem definido e socialmente visível. Implica a participação em um sistema de atividade sobre a qual os participantes compartilham entendimentos sobre o que eles estão fazendo e o que isso significa em suas vidas e em suas comunidades. (Lave et al., 1991, p. 98).

Nesta perspectiva, entendemos que as comunidades são constituídas a partir de configurações sociais, nas quais seus membros desenvolvem os empreendimentos por meio da participação periférica legítima no desenrolar de atividades que geram aprendizagem no intuito de contribuir com a constituição da identidade do membro aprendiz ${ }^{7}$, que vai acumulando experiência. Com o passar do tempo esse indivíduo passa a ser um membro ativo na comunidade, como nos asseveram Lave et al. (1991).

De igual modo, são esses empreendimentos desenvolvidos, tanto individual quanto coletivamente, que devem ser valorizados e compartilhados, pois favorecem a constituição ou a recreação de identidades. Isso contribui de modo que as comunidades sejam uma unidade diferenciada, harmônica e com laços efetivos.

Vale ressaltar que o termo 'comunidade' tem distintos significados, ele guarda sensações diversas como de boa ventura para os indivíduos que vivem em contexto de comunidade ou para aqueles que desejam fazer parte dela. Assim, "o que quer que 'comunidade' signifique, é bom 'ter uma comunidade', 'estar numa comunidade'. [...] As companhias ou a sociedade podem ser más; mas não a comunidade. Comunidade, sentimos, é sempre uma coisa boa" (Bauman, 2003, p. 7).

No que tange aos povos indígenas, em particular para os Xerente, comunidades são todos os espaços físicos do seu território, incluindo a floresta, a terra, a água, o céu e todas as criaturas que vivem nesses espaços, ou seja,

A comunidade também é a minha aldeia, a minha casa, a escola, o campo de futebol, o pátio, tudo isso aqui..., A comunidade para os Akwẽ são os lugares onde ocorre a transmissão de saberes, onde se vive a cultura (Ancião Severo Sõwarê, fev. 2015 in Melo,2016, p. 60).

Nessa direção, as comunidades se constituem em espaços ou contextos físicos, que agregam os indivíduos como eles são, fazendo parte dela desde a sua constituição, ou seja, desde seu nascimento; outros integram a comunidade pelos seus objetivos, empreendimentos e repertórios compartilhados. Os espaços da comunidade se caracterizam como:

um lugar "cálido", um lugar confortável e aconchegante. É como um teto sob o qual nos abrigamos da chuva pesada, com uma lareira diante da qual esquentamos as mãos num dia gelado. [...] E ainda: numa comunidade podemos contar com a boa vontade dos outros. Se tropeçarmos e cairmos, os outros nos ajudarão a ficar de pé outra vez. Ninguém vai rir de nós, nem ridicularizar nossa falta de jeito e alegrar-se com nossa desgraça. Se dermos um mau passo, ainda podemos nos confessar, dar explicações e pedir desculpas, arrepender-nos se necessário; as pessoas ouvirão com simpatia e nos

\footnotetext{
7 Refere-se aos primeiros estágios de aprendizagem pela observação para participar e realizar a prática em comunidades de prática.

Zetetiké, Campinas, SP, v.26, n.1, jan./abr. 2018, p.59-74

ISSN 2176-1744
} 
DOI: https://doi.org/ 10.20396/zet.v26il.8650844

perdoarão, de modo que ninguém fique ressentido para sempre. (Bauman, 2003, p. 7$8)$.

Esse olhar nos permite também compreender o termo 'comunidade' como um espaço físico, agregando pessoas que compartilham distintos saberes provenientes de contextos históricos, sociais e culturais articulados entre si, de modo a desenvolver habilidades e competências, gerar a troca, a reciprocidade e o conhecimento dos membros participantes da comunidade.

Todavia, Wenger (2001) destaca que uma comunidade se fortalece por meio das práticas de seus membros, e que estas unem os membros à comunidade. Nessa perspectiva, o termo 'prática' é assumido no contexto da teoria de comunidades de prática para descrever o desenvolvimento do conhecimento humano, tanto no campo teórico como no prático do saber e fazer na prática. Entretanto,

Teorizar sobre a prática social, a práxis, a atividade e o desenvolvimento do conhecimento humano por meio da participação em um mundo social faz parte de uma longa tradição marxista das ciências sociais. [...] Resumidamente, uma teoria social da prática enfatiza a interdependência relacional da pessoa com o mundo, com a atividade, ou seja, com a cognição, com a aprendizagem e com o conhecimento. Ressalta [ainda] o caráter inerentemente socialmente negociado do significado e o caráter preocupado, interessado, o pensamento e a ação das pessoas em atividade. (Lave et al.,1991, p. 50).

Chama-nos a atenção, o fato do conceito do termo 'prática' abranger várias ações que o ser humano executa em suas tarefas laborais e diárias, tanto no âmbito coletivo como no individual, independente do contexto social em que tais práticas são desenvolvidas. Nesse processo se destaca o caráter cognitivo dos indivíduos que realizam essas práticas e negociam novos empreendimentos de modo a objetivar os significados que são empreendidos.

Entretanto, Wenger (2001), ressalta a importância de se olhar a prática, não somente pelo caráter funcional das atividades humanas, haja vista que no desenvolvimento das atividades está o saber fazer na prática, não se tratando de ser um fazer em si mesmo, mas, o fazer advindo do contexto histórico e cultural, pois, fornece estrutura e significado a tudo que a humanidade vivencia, ou seja, o termo 'prática' remete a uma prática social. Nesta perspectiva, esse conceito inclui, ainda:

os aspectos explícitos como os implícitos, o que falar e o que não falar, o que se apresenta e o que é suposição, a linguagem, os instrumentos, os documentos, as imagens, os símbolos, os papéis bem definidos, os critérios específicos, os procedimentos codificados, os regulamentos e contratos que várias práticas tornam explícitas para uma variedade de propósitos. (Wenger, 2001, p. 71).

Desse ponto de vista conceitual, a prática enfatiza a aprendizagem num processo que aglomera o indivíduo como um todo, por meio do vivenciar, do conhecer, da experiência, do agir relacionado ao saber e ao fazer que se processa na prática, como "o processo de participar de uma prática sempre implica a toda pessoa, atuar e conhecer ao mesmo tempo" (Wenger, 2001, p. 72). 
Desta conceituação, acreditamos que as práticas socioculturais desenvolvidas pelo povo Xerente, em diferentes estágios da vida nas comunidades familiares ou comunitárias, unem e fortalecem os Xerente como um povo distinto culturalmente em seus repertórios de saberes linguísticos e de manifestação sociocultural; o que é evidenciado nas diversas formas de aprendizagem, de produção e de reprodução dessas práticas que envolvem todo o núcleo familiar na transmissão do conhecer, do ensinar e do aprender a prática seguindo critérios específicos dos pertencimentos às metades exogâmicas patrilinear ${ }^{8}$. Assim,

Para nós Akwẽ todos os nossos parentes podem ensinar as crianças pertencentes a sua metade clânica das pinturas corporais das toras grandes, dos cantos, danças, as histórias dos mitos. As crianças desde pequenas aprendem a ouvir, a ter obediência a respeitar a cultura, as obrigações do seu partido. Quando ensinamos às crianças na cultura e na linguagem, elas crescem aprendendo os nossos saberes na prática do dia a dia, não precisamos de um tempo para ensinar cada saber da nossa cultura. Não temos um tempo para ensinar isso ou aquilo, elas vão vivendo cada saber na prática, porque todo dia na aldeia, ou seja, na casa, no pátio, no rio, roça, nas colheitas de frutas do cerrado, nas noites de lua cheia as famílias também se reúnem para contarem histórias, na caçada, na pescaria, até no campo de futebol e na escola, tem sempre um $A k w e \tilde{~ f a z e n d o ~ a l g o ~ q u e ~ e ́ ~ p r o ́ p r i o ~ d a ~ n o s s a ~ c u l t u r a ~ X e r e n t e . ~ A s s i m, ~ a ~ t o d o ~ m o m e n t o ~ d o ~}$ dia ou da noite as crianças, e nós também, os adultos, estamos ensinando e aprendendo na prática os saberes e fazeres deixados pelos nossos antepassados (Nelson Hkawe Xerente \& Romário Sapkakõ Xerente, jan. 2016 in Melo 2016, p. 107).

Como é perceptível, ao atuar em determinada prática, o indígena Xerente está, também, desenvolvendo ações específicas dessa prática, de modo que produzirá diferentes empreendimentos; propiciando, nessas práticas, diversos aspectos característicos do saber e fazer nos processos de participação, negociação e engajamento das tradições socioculturais, podendo ou não gerar um novo empreendimento para o contexto no qual são concebidos. Dessa atuação, compreendemos que seja a participação do indígena no desenvolvimento da prática, o motivo pelo qual a mesma evolui no contexto da comunidade de prática, haja vista que:

Uma prática efetiva evolui com a comunidade como um produto coletivo. É integrada no trabalho das pessoas. Organiza o conhecimento, de uma forma que é especialmente útil para os profissionais porque reflete sua perspectiva. Cada comunidade tem uma maneira específica de fazer sua prática visível pelos meios que desenvolve e compartilha conhecimento. (Wenger, Mcdermott \& Snyder; 2002, p. 39)

Portanto, as ações são compartilhadas pelos indígenas em atividades práticas e coletivas, balizadas pelo diálogo, pela interação e pelo engajamento existente entre os

\footnotetext{
${ }^{8}$ Sistema tradicional Xerente de organização dos filho(s) e filha(s) nas práticas e nos fazeres socioculturais do pai.

${ }^{9}$ Todas as citações de Wenger, Mcdermott \& Snyder (2002), descritas neste artigo, são traduções nossas do inglês para o português, a partir da leitura compreensiva.

Zetetiké, Campinas, SP, v.26, n.1, jan./abr. 2018, p.59-74

ISSN 2176-1744
} 
indígenas no momento de desenvolvimento dessas práticas. Além disso, propicia atividades relacionadas à aprendizagem de conhecimentos característicos da comunidade.

Das ideias conceituais nas comunidades de prática, depreende-se que a prática é o elemento chave resultante de um conjunto de ações, de saberes, de fazeres, de métodos, de ferramentas e de demais características, conforme sugerem Wenger et al. (2002); são constituídas, experimentadas e negociadas ao longo da história da comunidade, de modo a defini-la como uma comunidade de prática.

Nesse cenário, consideramos as práticas socioculturais do povo Xerente investigadas e elucidadas pela negociação dos empreendimentos compreendidos nos saberes tradicionais e nos fazeres da prática, de modo a constituir esse povo em uma comunidade de prática sociocultural.

De fato, os processos próprios de organização social e cultural dos indígenas Xerente, ao interagem entre si, permitiram discutir e refletir sobre suas práticas tradicionais de pertencimento clânico. E, ainda, negociarem empreendimentos conjuntos que os conduzissem ao engajamento na realização das práticas, tanto no contexto social da comunidade como nos espaços mais amplos nos quais ocorrem as atividades de manifestação cultural.

No decurso da observação versus participação durante a realização das práticas socioculturais nas aldeias Porteira e Salto, notamos que o compartilhar de saberes, de fazeres, de conhecimentos e a negociação de empreendimentos foram mobilizados pelos indígenas no aprendizado e no desenvolvimento de seus repertórios, com vistas não somente às comunidades de prática; mas, também, em outros modelos de comunidade que colaboram entre si para manterem vivas suas tradições, em meio à dinâmica da modernidade, do capitalismo, do consumismo e da globalização tecnológica nos dias atuais.

Das interfaces teóricas e tradicionais para conceituar comunidades e prática, decorrem também as inter-relações epistemológicas, constituindo o povo Xerente - por meio de seus saberes e fazeres na prática - em uma comunidade de prática sociocultural. Nessa direção, conceituar comunidades de prática é retomar a história da humanidade, dos primórdios das antigas civilizações aos dias atuais e, assim, questionar: 'o que são comunidades de prática'? De modo igual, refletir sobre 'o que é uma comunidade de prática'? Logo,

Comunidades de prática não são uma ideia nova. Os conhecimentos primeiro basearam-se em estruturas sociais do período em que vivíamos em cavernas e as pessoas reuniam-se em torno do fogo para discutir estratégias para capturar a presa [animal], as formas de apontar a seta [das armas de captura], analisavam quais raízes eram comestíveis. [...] Mas, as comunidades de prática existem e se reproduzem em todos os aspectos da vida humana. (Wenger et al., 2002, p. 5).

Discutir comunidades de prática nesta perspectiva tem importância para os estudos e pesquisas que objetivam compreender como o ser humano constrói o conhecimento em interação cultural e social, em contextos diversos de linguagem e de simbologia visual. Esse panorama nos ajudou a compreender melhor o povo indígena Xerente, pois, juntamente com 
os pressupostos teóricos que subsidiaram esta pesquisa, revelou as dimensões do termo "comunidades de prática" como uma unidade, ao considerar que:

Todos [nós] pertencemos a comunidades de prática. Em casa, no trabalho, na escola, em nossas afinidades: pertencemos a várias comunidades de prática em qualquer momento dado. $\mathrm{E}$ as comunidades de prática a que pertencemos combinam com o curso de nossas vidas. Na realidade, as comunidades de prática estão por todas as partes. (Wenger, 2001, p. 23).

Todavia, ao assumirmos as práticas socioculturais dos indígenas Xerente, não significa dizer que essas práticas são aceitas como as práticas discorridas por essas teorias; entretanto, são convergentes, pois são provenientes das aprendizagens sociais e culturais desses indígenas. Da mesma forma que um determinado local social ou cultural frequentado pelos indígenas em um determinado tempo, caracteriza comunidades. E, ainda, nem toda comunidade caracteriza-se por meio das práticas que são compartilhadas. De igual modo, nem toda prática está impregnada pelo contexto da comunidade específica, ou seja,

Quando eu associo a prática e a comunidade, não estou dizendo que qualquer coisa que alguém possa chamar de comunidade é definida por uma prática ou tem uma prática específica, nem que tudo o que alguém pode chamar de prática é a propriedade definitiva de uma comunidade especifica. Na verdade, o que estou dizendo é que, associar prática e comunidade se fazem necessário duas condições essenciais, a saber:

1. produzir uma caracterização mais negociável do conceito de 'prática', especialmente distinguindo-a de termos menos negociáveis, como cultura, atividade ou estrutura;

2. definir um tipo de comunidade: uma comunidade de prática. (Wenger, 2001, p. 99).

No entanto, podemos afirmar com base na pesquisa de campo realizada nos contextos comunitários das aldeias Porteira e Salto, que o povo Xerente se constitui como uma comunidade de prática, visto que suas práticas fazem parte de um repertório de saberes e de fazeres socialmente transmitidos na oralidade da linguagem, nas expressões de simbologia visual e dos artefatos materiais e imateriais, das cosmologias místicas de criação e de organização social deste povo, desde os seus antepassados até as gerações presentes.

Essas práticas são vivenciadas em diferentes estágios da vida do $\mathrm{Ser}^{10}$ indígena, como nos espaços de aprendizagem, que ocorrem em distintos ambientes da comunidade, sob a liderança do núcleo familiar e são compartilhadas na vida social da comunidade.

Assim, os membros aprendizes vão se engajando aos mais experientes na realização das práticas da comunidade; de modo a conhecer, uma a uma, as práticas dos saberes e dos fazeres que compõem o repertório da tradição do povo Xerente. Essas aprendizagens são notórias, como observamos, em diferentes momentos temporais, quando refletimos sobre o

10 Assumimos este termo mediante os processos de atravessamento enfrentados pelos indígenas face aos distintos modos e processos educativos e formativos, que os constituíram como educadores indígenas. Destacando que esses processos distintos não afetaram a identidade do Ser indígena Xerente, ao contrário, fortaleceu a sua identidade cultural.

Zetetiké, Campinas, SP, v.26, n.1, jan./abr. 2018, p.59-74

ISSN 2176-1744 
saber fazer de uma prática da tradição Xerente, em particular as ocorridas durante a realização da grande festa Dasipse $\hat{e}^{11}$, conforme nos relataram os anciãos Xerente $^{12}$ :

Aqui nesta festa estamos praticando os saberes da nossa tradição que são ensinados em diferentes momentos da vida dos $A k w \tilde{e}$, desde os nossos antepassados aos dias de hoje. É assim, eu, ele e todos nós [os anciãos], os pais e a família vamos contando as histórias da cultura do povo Xerente. [...] as histórias são de nossas origens, os cantos e danças retratam a relação com a natureza e o céu, das lutas travadas com os não indígenas - para mantermos nosso território. Durante a festa, seja aqui no pátio, ao lado dessa fogueira, nas reuniões das associações de clãs Daksu: Krara, Annrõwa, Krêrêkmô e Akennhã, nas casas, no banho de rio, em cada canto da aldeia, da comunidade tem alguém repassando na oralidade e na prática esses e outros saberes para as crianças, jovens e para nós, os velhos. Desta forma, estamos fortalecendo e preservando a cultura tradicional dos Xerente. É bom dizer [...] antes tínhamos poucas aldeias e quando chegava perto do tempo da grande festa Dasipsê, sempre no início do verão, os anciãos se reuniam para escolher a aldeia que iam fazer a festa. Depois todo o povo Xerente se reunia para ajudar a preparar a festa. Assim, definiam todos os rituais da cultura que iam acontecer durante a festa cultural. Hoje são muitas aldeias e isso tem dificultado um pouco a vinda dos parentes de outras aldeias, mas, mesmo assim, a cultura ainda se mantém viva por meio da oralidade das práticas das pinturas corporais, das corridas de toras de buriti masculina e feminina, dos ritos de nominação, dos cantos e danças tradicionais. São tantos os nossos saberes que são praticados e vividos pelos $A k w \tilde{e}$, que fazem de nós um povo forte e guerreiro (in Melo, 2016, p. 110).

No decorrer desse processo de manifestação, os saberes e os fazeres da tradição do povo Xerente são expressados na oralidade e na prática, revigorando os indígenas por meio da força e da vida advindas dessas práticas, propiciando distintas relações de ensinar e de aprender culturalmente no cerne da comunidade de prática sociocultural. Assim, os indígenas interagem, trocam experiências e compartilham um repertório, de modo que os membros das metades exogâmicas Doi e Wahirê promovam relações interpessoais e sociais.

Miguel \& Mendes (2010), também pautados na teoria de comunidades de prática, assumem o termo 'práticas' em um sentido amplo, que vai desde os saberes próprios aos que são difundidos por uma única pessoa ou por um grupo de pessoas em diferentes contextos, compreendo-a como uma prática social da comunidade.

Dessa perspectiva decorre, dentre outras, a interação social, comunitária e de aprendizagem que envolve as relações pessoais, que evolui constantemente pela participação ativa dos membros na comunidade que agregam interesses comuns às práticas desenvolvidas, evidenciando em seus participantes, um sentimento de pertencimento à comunidade. Temos, então, que,

Comunidades de Prática são grupos de pessoas que compartilham uma preocupação, um problema comum ou uma paixão sobre determinado assunto e que aprofundam os seus conhecimentos e experiências, interagindo em uma mesma base. Essas pessoas

\footnotetext{
${ }^{11}$ Festa tradicional indígena Xerente, de manifestação cultural, de ensinamento e de transmissão de saberes e de fazeres na prática desse povo.

${ }^{12}$ Este relato foi compartilhado por Mmiro Xerente, Valdeciano Kasumrã Xerente, Basílio Bbazanô Xerente e Santino Sitmõru Xerente, em julho de 2015, por ocasião do trabalho de campo, na aldeia Salto, período em que, também, estava sendo realizada a tradicional festa grande do Dasĩpê.
}

Zetetiké, Campinas, SP, v.26, n.1, jan./abr. 2018, p.59-74

ISSN 2176-1744 
DOI: https://doi.org/ 10.20396/zet.v26il.8650844

não necessariamente trabalham juntas todos os dias, mas se encontram porque agregam valor em suas interações. [...] Ao longo do tempo, as pessoas desenvolvem uma perspectiva única sobre o seu tema, bem como um corpo de conhecimento comum, práticas e abordagens. Elas também desenvolvem relacionamentos pessoais e formas estabelecidas de interagir. Podendo desenvolver uma identidade e constituir uma comunidade de prática. (Wenger et al., 2002, p. 4-5).

Esta conceituação só reforça que o povo Xerente é uma comunidade de prática, mas é importante ressaltar que a mobilização de relações, de interações pessoais e de interesses comuns realizada no cerne das comunidades sem ter um objetivo coletivo, não caracteriza comunidades de prática, mas sim grupos de trabalhos diversos ou arranjos alternativos, porém, coletivos, em que as pessoas desenvolvem atividades em conjunto, com objetivos individuais.

Todavia, estes grupos ou arranjos alternativos e coletivos a depender das atividades que são realizadas, têm data de início e de fim, podendo voltar a existir a qualquer momento, dependendo do interesse das pessoas que organizaram esses grupos, com fins próprios para realizarem as atividades que surgem espontaneamente, sem nenhum vínculo a um contexto social e cultural. Ao contrário do que ocorre nas comunidades de prática não indígenas, os Xerente estão engajados por suas habilidades e capacidades, a fim de cumprir os objetivos coletivos ora estabelecidos por meio da participação e pelo diálogo de todos os membros da comunidade.

Portanto, é a partir da agremiação dos termos comunidade e prática, e das três dimensões da prática, decorrentes da aprendizagem em contextos sociais e culturais, que se constituem as comunidades de prática do povo Xerente, cujo engajamento não é uma ação resultante de uma atividade, mas fruto do coletivo, da comunidade como um todo.

Nesse sentido, a organização sociocultural desse povo é de responsabilidade mútua, tendo empreendimentos conjuntos, definidos pelos membros das metades exogâmicas Doi e Wahirê e negociadas no coletivo, as práticas socioculturais a serem realizadas. Práticas essas que compõem o repertório dos fatos históricos socialmente produzidos, transmitidos e interconectados às vivências dos indígenas Xerente em suas comunidades de prática. Contexto este, elucidado nos percursos metodológicos desta pesquisa.

\section{Percursos metodológicos}

Para respondermos nossa questão de pesquisa, a saber: Em que termos os saberes e fazeres das práticas socioculturais de pertencimento nas metades exogâmicas patrilineares Doi e Wahirê mobilizam aprendizagens matemáticas para as escolas indígenas Xerente? Seguimos um fio condutor, objetivando: Investigar as matemáticas que constituem o repertório compartilhado, em comunidades de prática das simbologias encontradas nas pinturas corporais Doi e Wahirê, pelos indígenas Xerente. 
DOI: https://doi.org/ 10.20396/zet.v26il.8650844

A investigação ocorrida no decurso dos anos de 2013 a 2016 foi assumida na perspectiva da abordagem qualitativa pautada na pesquisa etnográfica, sugerida por Oliveira (2010), dado o fato do contexto no qual se desenvolveu possuir uma dinâmica plural, intercultural e intracultural, na acepção de D'Ambrosio (2004). Características estas, evidentes nas aldeias Porteira e Salto do povo Xerente, ocupantes das terras indígenas Xerente e Funil.

O desenvolvimento metodológico desta investigação foi conduzido e permeado desde as vias adversas até o usual, proposto pela academia; em outras palavras, ora tínhamos os nossos procedimentos seguindo diretrizes e normas acadêmicas, ora éramos conduzidos pelos procedimentos tradicionais dos colaboradores, que nos evidenciavam as informações e seus significados por meio de atividades práticas por eles realizadas.

Sobre esses distintos procedimentos metodológicos, Lave (2001) afirma que em determinados contextos sociais e culturais não se admite aprendizagem sem uma prática cotidiana, por isso, muitas vezes fomos atravessados não somente pelas informações, mas, também, pelas práticas do saber fazer e do reproduzir na prática e pelos saberes tradicionais do povo Xerente em suas comunidades de práticas socioculturais.

Todos esses procedimentos se fizeram necessários para que conduzíssemos a contento a investigação, na perspectiva de constituirmos as bases epistemológicas, conceituais, etnográficas e interpretativas, que convergiram para a sistematização das informações recolhidas e posteriormente analisadas, a partir da interação e da vivência diária dos colaboradores em suas comunidades de práticas culturais.

Assim, destacamos o procedimento metodológico que nos conduziu durante a realização desse estudo investigativo, a saber: a descrição das informações recolhidas a partir da participação para observar e do observar para participar como indica Guber (2012). Tais informações permitiram compreender a complexidade dos saberes socioculturais e, em colaboração com os indígenas, refletir sobre as potencialidades cognitivas, criativas e educativas para o ensino das matemáticas nas escolas indígenas Xerente, com as simbologias encontradas nas pinturas corporais das metades clânicas Doi e Wahirê. Ademais, esse procedimento face a teoria de comunidades de prática, subsidiou as análises das informações de forma reflexiva, com os membros das aldeias pesquisadas.

\section{Da prática do saber fazer na prática das pinturas corporais das metades clânicas Doi e Wahirê às matemáticas Xerente}

As informações recolhidas a partir do ato de observar para participar, na acepção de Guber (2012) e nas três dimensões da prática indicadas por Wenger (2001), evidenciaram que os indígenas Xerente possuem empreendimentos constituídos de saberes e de fazeres tradicionais, compartilhados de geração a geração nesse povo, contribuindo com o engajamento mútuo e coletivo dos indígenas na realização das práticas do saber fazer na 
prática, com destaque aos mais diversos repertórios durante os processos de aprendizagens socioculturais.

Assim, os Xerente são organizados socioculturalmente em duas metades (ou partidos) exogâmicas regidas por sub partidos ou subclãs, de filiação patrilinear, chamadas de Doi e Wahirê, que significam Sol e Lua e fazem parte da cosmologia mística de criação deste povo. Estas metades são duais e se complementam na harmonia da reciprocidade compartilhada pelos seus membros.

Estas metades exogâmicas possuem seis subdivisões clânicas distribuídas da seguinte forma: Kuzâ, Kbazi e Krito pertencem à metade Doi - Isaptotdêkwainõrĩ (clã dono das bolinhas/círculos - kritoizapto), e se caracterizam visualmente pela pintura corporal, nas quais se destacam figuras geométricas similares ao círculo, chamadas pelos indígenas de bolinhas (pequena ou miúda, médio, grande ou graúdo) e, Wahirê, Krozake e Krãiprehi pertencem à metade Wahirê - issake tdêkwainõrĩ (clã dono das listras - îhirê/traço). Também fazem uso de segmentos de reta que denominam como traço (traços retos sendo uns finos entre os retos grossos e outros com pequenos traços horizontais e três traços finos retos entre os retos grossos), conforme ilustrado na Figura 01.

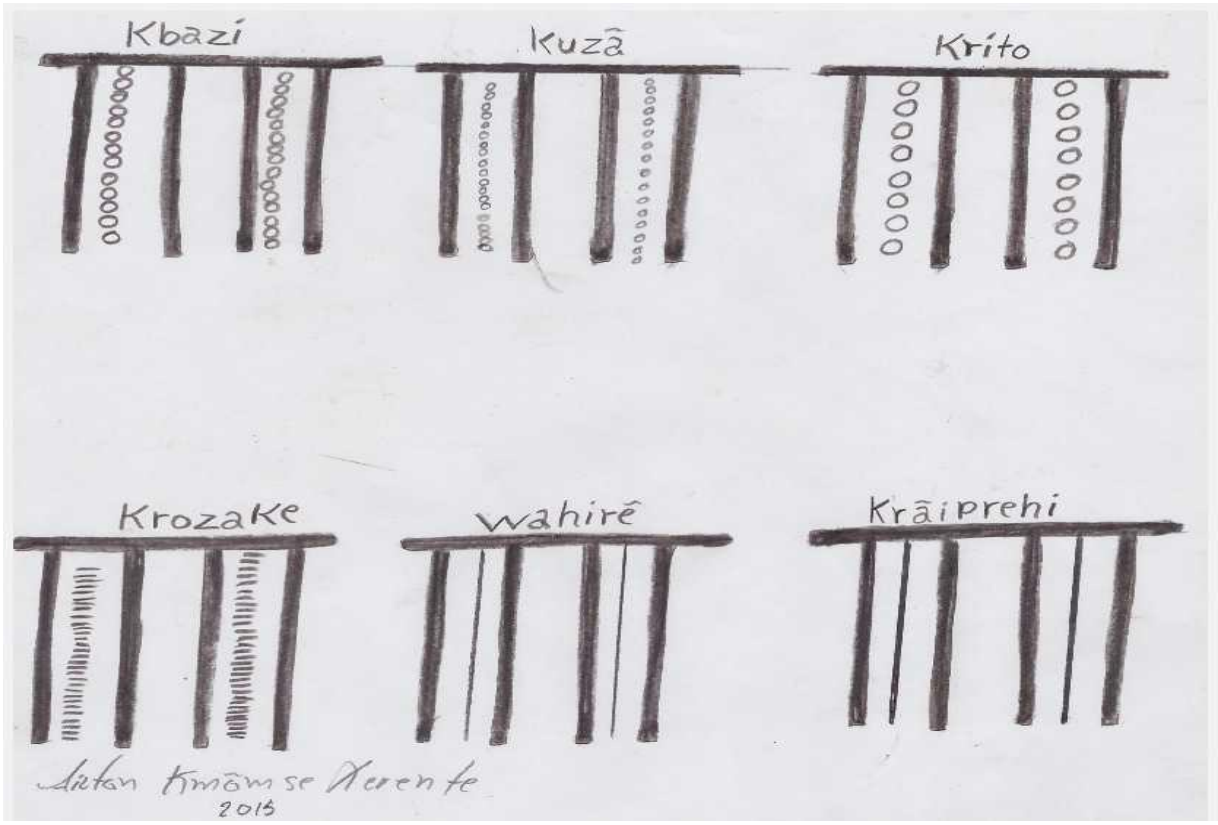

Figura 01: As metades exogâmicas patrilineares - Doi e Wahirê.

Autoria: Ailton Kmõmse Xerente, jul. 2015.

Fonte: Melo (2016, p. 61).

É a partir deste contexto de pertencimentos em metades clânicas patrilineares que os Xerente são reconhecidos desde crianças, em diferentes espaços de convívios diários, tanto os de sua aldeia, como em outras, assim como entre os demais povos indígenas dessa região, por meio das simbologias encontradas nas pinturas corporais clânicas das metades e suas subdivisões entre os Doi (bolinhas -kritoizapto/círculo) e os Wahirê (listra-îhirê/traço). 
As investigações sobre as matemáticas presentes nesta prática sociocultural das pinturas corporais Xerente, tomam como base os estudos realizados por Melo (2016). Portanto, cabe-nos, então, inventariarmos entre os desenhos ou padrões das iconografias de um repertório compartilhado proveniente da especificidade clânica das metades patrilineares exogâmicas Doi e Wahirê, que são as listras ou os traços e os círculos ou as bolinhas.

Desta perspectiva, as análises aferidas por Melo (2016) sobre as simbologias encontradas nas pinturas corporais dos clãs Doi - Sol e Wahirê - Lua, sinalizam possibilidades de estudos investigativos das geometrias a partir dos desenhos clânicos de cada metade exogâmica, expressados nos corpos dos indígenas, conforme ilustrou a Figura 01. Destacamos algumas dessas possibilidades: as grandezas de medidas podem ser estudadas considerando o tamanho e altura que os desenhos ocupam nos corpos dos indígenas; a ideia de grande e de pequeno expressa pelos indígenas durante a realização das pinturas corporais; espaço e forma com os estudos círculo e circunferência; distância entre um traço (reta), bolinha (círculo ou circunferência); dentre outros conceitos matemáticos presentes nestas pinturas clânicas, desde que negociadas com a comunidade indígena, em especial, os anciãos.

E, ainda, conforme ressalta Melo (2016), sob o prisma do ensino e da aprendizagem das matemáticas centradas no contexto local, entre os desenhos da metade clânica Doi que são as bolinhas-kritoizapto/círculo e os da metade clânica Wahirê que são as listraîhirê/traço, pode-se redimensionar o ensino e aprendizagem com horizontes para além das fronteiras da aldeia, dos núcleos familiares e das atividades de manifestação cultural, isto é, chegando aos espaços das escolas indígenas, a partir da construção de um ponto inicial (centro) que, ampliando-se em direção a horizontes mais largos (linha da circunferência), jamais perdem os movimentos (circulares) e o centro de convergência (ponto de partida) que são os estudos das práticas socioculturais interconectadas à Matemática escolar.

\section{Considerações finais}

No presente texto, tivemos como objetivos, dentre outros, o de retomar alguns empreendimentos por nós identificados durante a pesquisa de doutorado, no contexto comunitário das aldeias Porteira - Nrõzawi e Salto - Kripêe, sobre as práticas de pinturas corporais nas metades clânicas exogâmica patrilineares Doi e Wahirê, destacados por desenhos entre listra - îhirê/traço e bolinhas - kritoizapto/círculo, e toda a lógica de constituição e de organização tradicional na prática do saber fazer na prática do povo Xerente, em comunidades de prática.

Na perspectiva de responder à questão temática proposta neste estudo, destacamos que as práticas de pertencimento dos indígenas, nas metades Doi e Wahirê, são vitais para o fortalecimento da cultura Xerente, pois operam dentro de um repertório compartilhado de saberes em comunidades de prática, pautado na intraculturalidade, tanto dos saberes próprios apreendidos nos núcleos familiares e na realização das práticas de manifestação socioculturais quanto dos conhecimentos advindos do contato com o não indígenas e pelos 
processos de educação escolar indígena.

Entretanto, as práticas socioculturais das pinturas corporais propiciam aos indígenas, independente de sua filiação clânica, a interação e o compartilhar de saberes e de fazeres por meio do engajamento na prática de pintar seus corpos com os desenhos referentes às suas metades clânicas. É, assim, evidenciado um empreendimento pelo ato da destreza dos indígenas nessa prática, trazendo em si os ensinamentos de um povo com a base patrilinear a partir um repertório de saber e de fazer socialmente transmitidos na oralidade da linguagem, nas expressões de simbologia visual e nos artefatos materiais e imateriais, nas cosmologias místicas de criação e de organização social deste povo, desde os seus antepassados às gerações presentes, envolvendo todo o núcleo familiar.

E ainda, a prática das pinturas corporais em listra-îhirê/traço e bolinhas kritoizapto/círculo trazem, em si, um sistema de matemáticas Xerente, conforme foram as análises e as descrições ilustradas anteriormente na Figura 01, que podem ser problematizadas no ensino e na aprendizagem matemática dos estudantes, desde que negociadas com a comunidade, em especial, os anciãos, e a partir de um planejamento compartilhado com os educadores, pois, estes dispõem de conhecimentos necessários e provenientes de sua cultura para intermediar as relações assimétricas de ensino e de aprendizagem das matemáticas na escola indígena.

\section{Referências}

Bauman, Z. (2003). Comunidade: a busca por segurança no mundo atual. Trad. Plínio Dentzien. Rio de Janeiro: Zahar.

Brasil (2005). Secretaria de educação continuada, alfabetização e diversidade. Referencial Curricular Nacional para as Escolas Indígena - RCNEI. 2. ed. Brasília: MEC/SECADI.

D’ambrosio, U. (2004). Etnomatemática e educação: alguns elementos de reflexão. In G. Knijnik, F. Wanderer \& J. C. Oliveira, Etnomatemática: currículo e formação de professores. (pp. 39-52). Santa Cruz do Sul: Edunisc.Guber, R. (2012). La etnografia: método, campo e reflexividad. Buenos Aires: Siglo Veintiuno. (Mínina).

Lave, J. (2001). La práctica del aprendizaje. In S. Chaiklin \& J. Lave (Orgs.), Estudiar las prácticas: perspectivas sobre actividad y contexto. (pp. 15 - 45). Buenos Aires: Amorrortu. (Educación Agenda Educativa).

Lave, J. \& Wenger, E. (1991). Situated learning: legitimate peripheral participation. Cambridge: Cambridge University Press.

Melo, E. A. P. de. (2016). Sistema Xerente de Educação Matemática: negociações entre práticas socioculturais e comunidades de prática. Tese (Doutorado em Educação em Ciências e Matemáticas) - Universidade Federal do Pará, Belém.

Miguel, A. \& Mendes, I. A. (2010). Mobilizing histories in mathematics teacher education: memories, social practices, and discursive games. Revista ZDM mathematics education, (42), (381-392). Disponível em: http://link.springer.com/article/10.1007/s11858-010- 
DOI: https://doi.org/ 10.20396/zet.v26i1.8650844

0255-8.

Oliveira, M. M de. (2010). Como fazer pesquisa qualitativa. 3. ed. rev. amp. Petrópolis: Vozes.

Wenger, E. (2001). Comunidades de práctica: aprendizaje, significado e identidad. Barcelona: Editorial Paidos.

Wenger, E., Mcdermott, R. \& Snyder, W.M. (2002). Cultivating communities of practice. Harvard Business Schoo Press, 2002.

Recebido em: 29/10/2017

Aprovado para publicação em: 03/04/2018 